\title{
Konsep Akhlak dalam Islam dan Kontribusinya Terhadap Konseptualisasi Pendidikan Dasar Islam
}

\author{
Ahmad Sahnan \\ Institut Agama Islam Negeri ( IAIN) Purwokerto \\ sahnan@iainpurwokerto.ac.id
}

\begin{abstract}
This paper discusses akhlak concept and it's conceptualization of Islamic primary school. In Islam akhlak occupy a very vital position because it involves horizontal and vertical relations. Likewise in Islamic primary school akhlak becomes a pillar on other pillars. Akhlak determination is very important in setting educational goals, teaching practices, methods, infrastructure, values that are instilled and all implementation. When akhlak and values of Islam are not contained in education, it is certain that the pillars of education are impossible to realize properly. The akhlak contribution in the conceptualization of Islamic primary school; first, help formulate educational goals. Second, help in formulating the characteristics and content of the curriculum. Third, help formulate the characteristics of professional teachers. Fourth, help formulate a code of ethics and school discipline. Fifth, make teaching and learning activities that produce students have noble character. Sixth, creating a clean, orderly, safe, peaceful, comfortable, and conducive learning environment. Realization of the concept can be started with further teaching followed by habituation education, exemplary, practice, coupled with examples, as well as explanations, coaching to finally become characters.
\end{abstract}

Keywords: Akhlak, Akhlak Contributions, conceptualization, Islamic Primary school.

Abstrak. Tulisan ini membahas konsep akhlak dan konseptualisasinya terhadap pendidikan Dasar Islam. Dalam ajaran Islam akhlak menempati posisi yang sangat vital karena ia menyangkut hubungan horizontal dan vertikal. Demikian halnya dalam pendidikan Islam akhlak menjadi pilar di atas pilar lainnya. Penetapan akhlak sangat penting dalam penetapan tujuan pendidikan, peraktik mengajar, metode, sarana prasarana, nilai-nilai yang ditanamkan dan seluruh pelaksanaannya. Metode dalam tulisan ini bersipat library research dikumpulkan dari data-data yang ada. Adapun hasil dari tulisan ini

AR-RIAYAH : Jurnal Pendidikan Dasar vol. 2, no. 2, 2018

STAIN Curup - Bengkulu| pISSN2580-362X;e ISSN2580-3611

http://journal.staincurup.ac.id/index.php/JPD 
menunjukkan bahwa akhlak sangat berkontribusi dalam konseptualisasi pendidikan dasar Islam yakni sebagai berikut; pertama, membantu merumuskan tujuan pendidikan. Kedua, membantu dalam merumuskan ciri-ciri dan kandungan kurikulum. Ketiga, membantu merumuskan ciriciri guru profesional. Keempat, membantu merumuskan kode etik dan tata tertib sekolah. Kelima, menjadikan kegiatan belajar mengajar yang menghasilkan siswa mempunyai akhlak mulia. Keenam, menciptakan lingkungan pendidikan yang bersih, tertib, aman, damai, nyaman, suasana belajar yang kondusif. Terealisasinya konsep tersebut dapat diawali dengan pengajaran seterusnya dilanjutkan dengan pendidikan pembiasaan, keteladanan, pengamalan, dibarengi contoh, serta penjelasan, pembinaan hingga akhirnya menjadi karakter.

Kata Kunci: Akhlak, Kontribusi Akhlak, konseptualisasi, Pendidikan dasar Islam.

\section{PENDAHULUAN}

Berbicara tentang akhlak adalah pembahasan yang tidak ada habisnya. Topik tentang akhlak merupakan pembahasan yang selalu menarik untuk dibicarakan. hal ini disebabkan, akhlak yang baik kemudian akan berperan sebagai sistem perilaku yang akan menciptakan harmonisasi dalam kehidupan manusia. Sebagaimana akhlak terbagi kepada akhlak terpuji dan tercela, namun sayangnyaakhir-akhir ini akhlak tercela sering kita jumpai dalam berita yang menghiasi wajah televisi maupun dimedia masa tentang kemorosotan akhlak. Seperti halnya kasus pelecehan seksual, gaya hedonisme, tawuran, penganiyaan terhadap guru, tindakan korupsi dan sebagainya. Maraknya kasus-kasus demoralitas dan kemerosotan akhlak ini merupakan tanggung jawab kita bersama. Salah satu solusi pencegahan akhlak ini tercela ini dengan melalui pendidikan akhlak itu sendiri. Dengan mengembalikan defenisi dan menanamkan nilai-nilai akhlak yang sebenarnya. Tulisan ini menurut penulis bisa menjadi salah satu acuan dalam menjawab terkait kasus-kasus kemorostan akhlak. Maka dari itu penulis akan membahas tentang konsep akhlak dan konseptualisasinya terhadap pendidikan Dasar Islam.

\section{Pengertian Akhlak Dan Moral}

Kata akhlak merupakan bentuk jama` dari bahasa arab kbuluqun yang memiliki arti : sajiyyatun, tabi tun, atau 'adatun, yang artinya karakter, tabiat atau adat kebiasaan, atau disebut juga etika. Akhlak juga sering disebut dengan moral, 
dimana ia merupakan satu kali tindakan manusia yang diulang secara terus menerus, dan akhirnya menjadi adat kebiasaan yang menyatu dalam diri perilakunya. Pengertian akhlak dalam pengertinnya sangatlah luas tidak hanya sebatas pengertian sopan santun atau moral. Meskipun dalam hal ini diantara pakar ada yang berpendapat bahwa dalam pengertan antara kebiasaan dan moral, karena kebiasaan dapat didefenisikan sebagai adat istiadat yang tidak merugikan, sebagai contoh, (kebiasaan minum teh pada pagi hari), sedangkan moral adalah perlakuan terhadap orang lain. ${ }^{1}$

Perbuatan-perbuatan manusia dapat dianggap sebagai akhlak apabila memenuhi dua syarat sebagai berikut: pertama, perbuatan-perbuatan itu dilakukan berulang kali sehingga perbuatan-perbuatan itu menjadi kebiasaan. Kedua, perbuatan-perbuatan itu dilakukan dengan kehendak sendiri bukan karena adanya tekanan-tekanan yang datang dari luar seperti ancaman dan paksaan atau sebaliknya melalui bujukan dan rayuan. ${ }^{2}$ Tatanan akhlak tidak hanya terbatas pada penyusunan hubungan antara manusia dengan manusia lain, tetapi lebih dari itu juga mengatur hubungan manusia dengan segala yang terdapat dalam wujud dan kehidupan, dan lebih jauh lagi mengatur hubungan antara hamba dengan Tuhannya. ${ }^{3}$

Adapun Al-Toumi Al-Syaibani menjelaskan keistimewaan atau ciri akhlak Islam dalam tujuh kategori, yaitu universal, keseimbangan, kesederhanaan, (mengambil jalan tengah, tidak berlebihan dan berkurang), realistik (sesuai dengan kemampuan manusia dan sejalan dengan naluri yang sehat), kemudahan (tidak memberatkan kecuali dalam batas-batas kekuatannya), mengikat perkataan dengan amal dan teori dengan praktik, dan tetap dalam dasar-dasar dan prinsip-prinsip akhlak umum. ${ }^{4}$

Akhlak mempunyai tujuan ganda, menciptakan kebahagiaan dunia dan akhirat. Dalam kerangka tujuan akhlak untuk kebahagiaan ini, Imam al-Ghazali membagi kebahagiaan dunia menjadi empat bagian pokok, yaitu kebaikan

\footnotetext{
${ }^{1}$ Juwariyah, Pendidikan Moral Dalam Puisi Imam Syafi i dan Ahmad Syanqi, (Yogyakarta: Bidang Akademik, 2008), 274

${ }^{2}$ Rachman Assegaf, Filsapat Pendidikan Islam, (Jakarta: Raja Grafindo Persada, 2011), 42

${ }^{3}$ Semboro Ardi Widodo, Kajian Filosofis Pendidikan Barat dan Islam, Jakarta: Fifamas,2003), 166

${ }^{4}$ Ibid, 167
} 
badan, kebaikan jiwa, kebaikan luar, dan kebaikan dari Allah. Dan kebaikan yang tertinggi adalah kebahagiaan akhirat yang kekal dan tidak akan rusak. ${ }^{5}$

Sedangkan moral mengandung pengertian : baik, buruk, yang diterima umum mengenai perbuatan, sikap, kewajiban, dan lain sebagainya. Atau bisa juga berarti akhlak, budi pekerti, atau susila. Sedangkan menurut Peospoprodjo, bahwa moral adalah suatu kualitas dalam perbuatan manusia yang menunjukkan bahwa perbuatan itu benar atau salah, serta baik atau buruk. Moral juga dikatakan sebagai padanan dari etika, yang berasal dari bahasa Yunani ethos yang juga bermakna hukum, adat istiadat, kebiasaan, budi pekerti. Dengan demikian dapat dikatakan bahwa kata moral, etika, sopan santun, budi pekerti, akhlak, adat istiadat, undang-undang hukum, serta norma, semuanya itu mengandung makna atau pengertian, yang untuk tidak dikatakan sama tidak mengandung perbedaan yang berarti. ${ }^{6}$

Sistem moral adalah suatu keseluruhan tatanan yang terdiri dari dua atau lebih komponen yang satu sama lain saling mempengaruhi, atau bekerja dalam satu kesatuan, atau keterpaduan yang bulat, yang berorientasi kepada nilai dan moralitas islam. ${ }^{7}$ Oleh karena itu pendidikan Islam bertujuan pokok pada pembina akhlak mulia, maka sistem moral islami yang ditumbuhkembangkan dalam proses kependidikan adalah norma yang berorientasi kepada nilai-nilai islami. Islam menuntut manusia agar melaksanakan sistem kehidupan yang didasarkan atas norma-norma kebajikan dan jauh dari kejahatan. Ia memerintahkan perbuatan yang makruf dan menjauhi kemungkaran, bahkan manusia dituntut agar menegakkan keadilan dan menumpas kejahatan dalam segala bentuknya. Sistem moralIslam, dengan demikian, berpusat pada sikap mencari rida Allah, pengendalian nafsu negatif, dan kemampuan berbuat kebajikan serta menjauhi perbuatan jahat. ${ }^{8}$

Dalam agama Islam penggunaan kata akhlak, moral, etika sangat dibedakan karena dalam Islam penggunaan akhlak sangat luas tidak hanya sekedar sopan santun, budi pekerti, moral dll. Sedangkan dalam Islam berkenaan dengan manusia selaku hamba Allah, akhlak manusia terhadap Allah menempati kedudukan yang sangat sentral dan vital. Rasul bersabda dalam hadis : (aku diutus tiada lain hanya untuk menyempurnakan kebaikan akblak). Atau yang

${ }^{5}$ Ibid, 168

Guwariyah, Pendidikan moral....., 234

${ }^{7}$ Muzayyin Arifin, Filsapat Pendidikan Islam, (Jakarta: Bumi Aksara, 2003), 126

${ }^{8}$ Ibid, 129 
semakna dengan ungkapan itu. Kalau pernyataan itu kita cermati, akhlak sebagai misi Rasulullah SAW. Yang bersipat menyeluruh, tentu mengandung arti yang sangat luas, seluas ajaran Islam yang beliau sampaikan. Paling sedidkit akhlak pasti mencakup lima hubungan: akhlak manusia dalam berhubungan dengan Allah, diri sendiri, keluarga, masyarakat dan alam. Tauhid harus menjadi jiwa ibadah. Tidak ada ibadah dan akhlak baik kepadanya tanpa tauhid. Pelanggaran terhadap ketauhidan dalam beribadah merupakan akhlak terburuk kepadanya, membuahkan dosa yang tidak terampun berbeda dengan dosa lainnya. ${ }^{9}$

Penjelasan di atas dapat kita ketahui bahwa moral etika lebih dominan dari manusia untuk manusia, moral/etika menyangkut hubungan horizontal (antropresentris) sedangkan akhlak menyangkut hubungan horizontal dan vertikal sekaligus. Selanjutnya dalam menentukan standar baik buruk dalam akhlak ialah agama yang sumbernya wahyu dan akal fikiran sekaligus. Adapun baik buruk diluar agama hanya ditentukan oleh perasaan, akal dan fikiran.Kemudian hubungan akhlak berangkat dari ketajaman perasaan/hati nurani/fuad serta akidah dan keimanan.

\section{Macam-macam Akhlak}

Dilihat dari segi hubungan manusia dengan dirinya, serta hubungannya dengan Tuhan, manusia dan lainnya, maka akhlak itu ada yang berkaitan dengan dirinya sendiri, dengan Tuhan, dengan manusia, dengan masyarakat, dengan alam, dan dengan segenap makhluk Tuhan lainnya yang ghaib. Akhlak dengan diri sendiri antara lain tidak membiarkan dalam keadaan lemah, tidak berdaya dan terbelakang, baik secara fisik, intelektual, jiwa, spiritual, sosial dan emosional. Akhlak terhadap diri sendiri dilakukan dengan cara membuat diri secara fisik dalam keadaan sehat, kokoh dan memiliki berbagai keterampilan mengisi otak dan akal fikiran dengan berbagai pengetahuan, mengisi jiwa dengan nilai-nilai keimanan dan ketakwaan, dan seni, mengisi jiwa dengan kemampuan bersosialisasi dengan masyarakat sekitarnya dan sebagainya. ${ }^{10}$

Adapun akhlak terhadap Tuhan antara lain dengan mengenal, mengetahui, mendekati, dan mencintainya, melaksanakan segala perintahnya

\footnotetext{
${ }^{9}$ Ahmad Janan Asifuddin, Mengikuti Pilar-Pilar Pendidikan Islam, (Yogyakarta: SUKAPress, 2010), 95-96

${ }^{10}$ Abuddin Nata, Pemikiran Pendidikan Islam dan Barat, (Jakarta: Rajawali Press, 2012), 209
} 
dan menjauhi segala larangannya menghiasi diri dengan sifat-sifatnya atas dasar kemampuan dan kesanggupan manusia, membumikan ajarannya dalam kehidupan individu, masyarakat dan bangsa. ${ }^{11}$

Ahmad Janan juga menyatakan bahwa hubungan Akhlak setidaknya terdapat akhlak kepada Allah, Rasullah, diri sendiri, keluarga, masyarakat, alam dan negara. Misalnya Akhlak terhadap Allah dengan mengamalkan seluruh ibadah wajib dan sebagai ibadah sunnah, dan menjauhi segala perbuatan syririk kepada-Nya. Terhadap diri sendiri seperti menjaga kesehatan, tidak merugikannya dan tidak membebani diri dengan beban yang terlampau berat diluar kemampuan. Kepada keluarga misalnya, menunaikan kewajiban kepada seluruh anggota lain, dan memberikan pendidikan agama benar-benar cukup bagi anak. Terhadap masyarakat, misalnya tolong menolong dalam kebaikan. Akhlak terhadap alam, seperti menjaga alam, mengelola, memelihara dan tidak merusaknya. Dan yang perlu di catat dalam hal ini, bahwasanya penjabaran hubungan akhlak di atas kesemuaannya dapat bernilai ibadah sepanjang mendapat ridha Allah dan disertai niat. ${ }^{12}$

\section{Prinsip Dasar Akhlak dan Moral Dalam Islam}

Dalamajaran Islam yang menjadi dasar-dasar akhlak adalah berupa alQur`an dan Sunnah Nabi Muhammad Saw. Baik dan buruk dalam akhlak Islam ukurannya adalah baik dan buruk menurut kedua sumber itu, bukan baik dan buruk menurut ukuran manusia. Sebab jika ukurannya adalah manusia, maka baik dan buruk itu bisa berbeda-beda. ${ }^{13}$ Seseorang mengatakan bahwa sesuatu itu baik, tetapi orang lain belum tentu menganggapnya baik. Begitu juga sebaliknya, seseorang menyebut sesuatu itu buruk, padahal yang lain bisa saja menyebutnya baik.

Semua ummat Islam sepakat pada kedua dasar pokok itu (al-Qur`an dan Sunnah) sebagai dalil naqli yang tinggal mentransfernya dari Allah Swt, dan Rasulullah Saw. Keduanya hingga sekarang masih terjaga keotentikannya, kecuali Sunnah Nabi yang memang dalam perkembangannya banyak ditemukan hadis-hadis yang tidak benar (dha'if/palsu).

\footnotetext{
${ }^{11}$ Ibid,

12Janan, Mengungkit Pilar, 96

${ }^{13}$ Marjuki, Akblak Mulia (Pengantar Studi Konsep-Konsep Dasar Etika Dalam Islam), (Yogyakarta: Debut Wahana, 2009), 34
} 
Melalui kedua sumber inilah kita dapat memahami bahwa sifat sabar, tawakkal, syukur, pemaaf, dan pemurah termasuk sifat-sifat yang baik dan mulia. Sebaliknya, kita juga memahami bahwa sifat-sifat syirik, kufur, nifaq, ujub, takabur, dan hasad merupakan sifat-sifat tercela. Jika kedua sumber itu tidak menegaskan mengenai nilai dari sifat-sifat tersebut, akal manusia mungkin akan memberikan nilai yang berbeda-beda. Namun demikian, Islam tidak menafikan adanya standar lain selain al-Qur`an dan Sunnah untuk menentukan baik dan buruknya akhlak manusia.

Selain itu standar lain yang dapat dijadikan untuk menentukan baik dan buruk adalah akal dan nurani manusia serta pandangan umum masyarakat. Islama dalah agama yang sangat mementingkan Akhlak dari pada masalahmasalah lain. Karena misi Nabi Muhammad diutus untuk menyempurnakan Akhlak. Manusia dengan hatinuraninya dapat juga menentukan ukuran baik dan buruk, sebab Allah memberikan potensi dasar kepada manusia berupa tauhid. Allah Swt. berfirman:
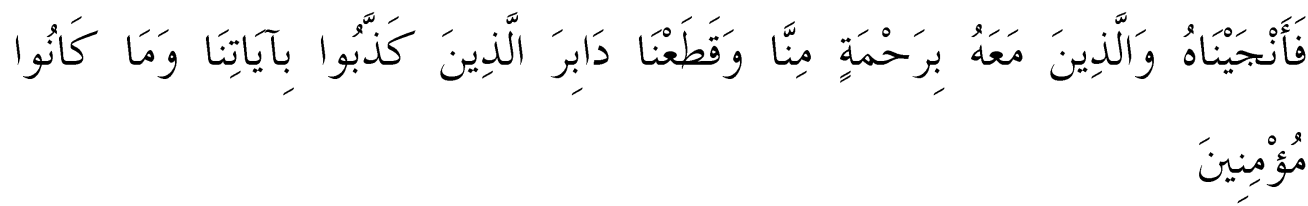

Artinya: "Dan (ingatlab), ketika Tuhanmu mengeluarkan keturunan anak-anak Adam dari sulbi mereka dan Allah mengambil kesaksian terhadap jiwa mereka (seraya berfirman): "Bukankah Aku ini Tuhanmu?" Mereka menjawab: "Betul (EngkauTuhan kami), kami menjadi saksi". (Kami lakukan yang demikian itu) agar di hari kiamat kamu tidak mengatakan: "Sesunggubnya kami (bani Adam) adalab orang-orang yang lengah terhadap ini (keesaan Tuhan)"." (QS. al-A'raf: 72).

Prinsip Akhlak dalam Islam terletak pada Moral Force. Moral Force Akhlak Islam adalah terletak pada iman sebagai Internal Power yang dimiliki oleh setiap orang mukmin yang berfungsi sebagai motor penggerak dan motivasi terbentuknya kehendak untuk merefleksikan dalam tata rasa, tatakarsa, dan tatakarya yang kongkret. Dalam hubungan ini Rasulullah Saw, bersabda:

"Orang mukmin yang paling sempurna imannya ialah yang terbaik akblaknya. Dan sebaik-baik diantara kamu ialah yang paling baik kepada istrinya" 
Selain itu yang menjadi dasar pijakan Akhlak adalah Iman, Islam, dan Islam. Al-Qur'an menggambarkan bahwa setiap orang yang beriman itu niscaya memiliki akhlak yang mulia yang diandaikan seperti pohon iman yang indah hal ini dapat dilihat pad asurat Ibrahim ayat 2426-, yang berbunyi:

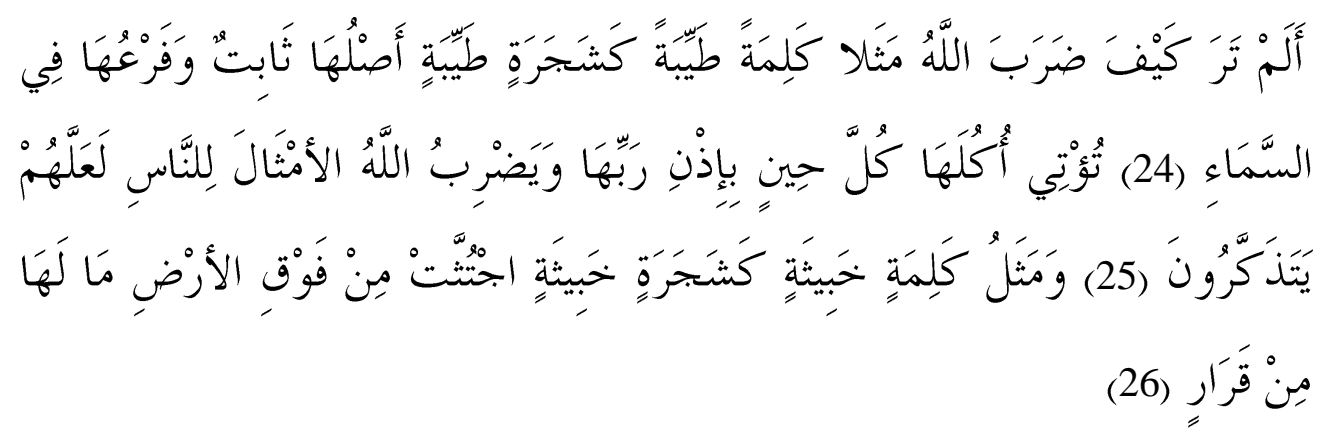

Artinya: "Tidakkah kamu perbatikan bagaimana Allah telah membuat perumpamaan kalimat yang baik seperti pohon yang baik, akarmya teguh dan cabangnya (menjulang) ke langit, pohon itu memberikan buahnya pada setiap musim dengan seizin Tuhannya. Allah membuat perumpamaan-perumpamaan itu untuk manusia supaya mereka selalu ingat. Dan perumpamaan kalimat yang buruk seperti pohon yang buruk, yang telah dicabut dengan akar-akarnya dari permukaan bumi; tidak dapat tetap (tegake) sedikit pun.”.

Dari ayat diatas dapat kita ambil contoh bahwa ciri khas orang yang beriman adalah indah perangainya dan santun tutur katanya, tegar dan teguh pendirian (tidak terombang ambing), mengayomi atau melindungi sesama, mengerjakan buah amal yang dapat dinikmati oleh lingkungan.Namun di sisi lain, sebenarnya masihb anyak eori-teori yang berbicara mengenai dasar-dasar akhlak dengan menafikan pemikiran Islam, seperti relativisme akhlak. Yang mana berkat pembuktian realisme, maka kemutlakan akhlak adalah pendapat yang sahih dan relativisme akhlak tidak dapat diterima.

Ada sebuah ungkapan yang mengatakan bahwa, kita akan memanen apa yang kita tanam. Dari ungkapan tersebut dapat kita tarik benangmerah, bahwasannya apa yang kita lakukan tidak ada hubungannya dengan sesuatu diluar diri kita, karena hubungan perbuatan kita berhubungan langsung dengan Tuhan. Tanpa adapihak ke-3. Oleh karena itulah dasar Ahklak memerlukan Disiplin Moral. 
Kant, filosof Jerman berpendapat bahwa Rasio Spekulatif, yaitu agendi dalam mekanisme tidak bernilai tinggi; namun rasio praktis, yaitu agen dari pelaksanaan hal-hal praktis, yang juga dimaknai sebagai "kesadaran akhlak" memiliki kegunaan yang pasti dan perintah-perintahnya bersifat mengikat. ${ }^{14}$ Dan halini sering di maknai sebagai "kesadaran akhlak".

Dari sekian banyak ayat-ayat al-Qur`an yang membahas tentang akhlak dan moral, ini ada beberapa ayat yang mewakili yakni bisa dilihat seperti yang tersebut dalam al-Qur`an surah al-Qalam: 4, al-Ahzab: 21, Fuhshilat: 34, alMu `minun: 96 dll. Dan juga hadis yang populer dikalangan kita "sesunggubnya aku diutus ke muka bumi ini untuk menyempurnakan akblak manusia " (H.R: Bukhari).

\section{Konseptualisasi Akhlak Terhadap Pendidikan Islam}

Posisi akhlak terhadap pendidkan Islam sangat penting dan menjadi pilar di atas semuanya. Tema ini sangat penting terhadap penetapan tujuan pendidikan, peraktik mengajar, metode, sarana prasarana, nilai-nilai yang ditanamkan dan seluruh pelaksanaannya. Karna bisa kita bayangkan ketika akhlak dan nilai-nilai islam tidak terdapat dalam diri seseorang maka kesemuan pilar-pilar pendidikan yang disebutkan di atas tidak akan dapat terealisasikan dengan baik. Sebagai contoh ketika seorang kepala sekolah tidak ada akhlak terhadap Allah dan dirinya dia akan melakukan korupsi terhadap sarana prasarna. Begitujuga dengan seorang guru ketika dalam dirinya tidak tertanam nilai-nilai akhlak Islam maka yang ada dalam dirinya hanya sekedar menyampaikan kewajibannya dengan mengajar saja tanpa memikirkan muridnya paham atau tidak. Begitujuga korupsi akan selalu meraja lela dalam negeri ini tanpa adanya penanaman nilai-nilai akhlak keislaman sekalipun pada dasarnya di Indonesia sudah mempelajari agama mulai dari sejak TK hingga tingkat Universitas.

Tentu jika kita berbicara tentang benang merah pendidikan Islam sangatlah mudah karena, nuansa akhlak merupakan sumber nilai, dan internalisasi nilai-nilai merupakan salah satu tugas pokok pendidikan Islam. Dan yang menyebabkan terjadinya seperti contoh di atas karena, pendidikan internalisasi seperti metode keteladanan, pembiasaan amal, tuntunan, metode

${ }^{14}$ QurbaniLahiji, Risalah Sang Imam (AjaranEtika Ali Bin AbiThalib), ( Jakarta: al-Huda, 
targhib wa tarhib dan cara-cara yang berorientasi pada pembentukan sikap kurang mendapat porsi. Implikasi pandangan Islam tentang akhlak mewajibkan pendidikan Islam agar membangun akhlak islamiah pada peserta didik, baik yang menyangkut hubungan dengan Allah maupun dengan manusia dan sesama makhluk ${ }^{15}$.

Adapun pengimplikasian akhlak dalam pendidikan dapat dimulai dari:

1. Pengajaran: artinya memberikan pengajaran secara konsep yang membahas tentang mana yang baik dan mana yang buruk, mana yang benar dan mana yang salah menurut ukuran agama, hingga mereka mampu membedakan diantaranya.

2. Pembiasaan: setelah memberikan pengajaran pembinaan selanjutnya dengan cara pembiasaan. Membiasakan hal-hal kebaikan dari sejak usia dini yang dilakukan secara kontinyu. Dengan pembiasaan hal-hal kebaikan seperti menebar kasih sayang terhadap sesama, suka menolong teman dalam hal kebaikan, dermawan akan mendarah daging dan menjadi sebuah karakter ketika nantinya dewasa.

3. Keteladanan: tercapainya pembinaan akhlak yang baik dapat ditempuh melalui keteladanan. Alangkah baiknya ketika seorang guru memberikan pengajaran dengan memberikan langsung keteladanan. Seumpama ketika guru mengajarkan sopan santun gur tersebut dalam keseharian menunjukkan sopan santun terhadap muridnya. Jika guru menyuruh mengerjakan sesuatu guru ikut terlibat dalam pekerjaan tersebut. Sebagaimana yang telah dicontohkan Nabi Muhammad SAW.

4. Paksaan : dalam hal ini paksaan yang bentuknya dalam hal kebaikan tanpa menyakiti secara fisik. Paksaan ini bertujuan untuk membiasakan peserta didik dalam melakukan hal-hal kebaikan yang nantinya setelah terbiasa merasa tidak dipaksa lagi. Sama halnya ketika seseorang dipaksa untuk membaca yang pada gilirannya nanti terbiasa membiasa membaca tanpa harus dipaksa lagi.

5. Hadiah dan hukuman: agar akhlak mahmudah dapat diamalkan dalam kehidupan sehari-hari peserta didik yang mengamalkan akhlak baik diberikan hadiah. Baik itu hadiah berupa materi maupun ungkapan kalimat yang menyenngkan hatinya dan memotivasi peserta didik lain untuk melakukan akhlak yang baik. Begitupun sebaliknya jika peserta

${ }^{15}$ Abuddin Nata, Akblak Tasawnf,142. 
didik yang melakukan akhlak mazmumah dengan memberikan hukuman yang sifatnya mengubah perilaku tercela kepada prilaku terpuji. ${ }^{16}$

\section{Kontribusi Akhlak dan Moral terhadap Pendidikan Dasar Islam (SD/MI)}

Pendidikan dasar Islam (SD/MI) merupakan salah satu jenjang pendidikan yang harus mendapatkan penanaman nilai-nilai pendidikan akhlak dan moral. Sebagai pendidikan awal dan dasar ini menjadi sangat penting. Peserta didik yang ada dalam jenjang ini merupakan masa keemasan bagi anak. Masa ini adalah masa yang sangat potensial dalam mengembangkan potensi dirinya. Oleh karena itu masa pendidikan dasar inilah mulai ditanamkan akhlakakhlak yang baik sehingga nantinya akan berkembang secara optimal ketika meranjak dewasa.

Sehubungan dengan itu akhlak dan moralitas memiliki kontribusi yang sangat penting terhadap pendidikan dasar Islam. untuk lebih jelasnya, kontrubusi akhlak terhadap pendidikan dasar Islam (SD/MI) dipaparkan sebagaimana berikut ini ${ }^{17}$ :

1. Merumuskan tujuan pendidikan: artinya, pemahaman tentang akhlak membantu merumuskan tujuan pendidikan, yaitu membentuk manusia agar memiliki akhlak mulia atau keperibadian yang utama yang ditandai oleh adanya integritas keperibadian yang utuh, satunya hati, ucapan dan perbuatan, memiliki tanggung jawab terhadap dirinya, masyarakat dan bangsanya, melaksanakan segala perintah Allah SWT, terbentuknya manusia yang baik, manusia yang berakhlak mulia, manusia yang sempurna, serta manusia yang berkepribadian muslim. Demikian halnya dalam tujuan pendidikan dasar Islam harus mengandung unsur akhlak mahmudah. Sehingga semua lini terintegrasi dengan baik. Stakeholder dalam pendidikan dasar Islam harus berakhlak mulia sehingga tujuan pendidikan dasar Islam berjalan dengan baik.

2. Merumuskan ciri-ciri dan kandungan kurikulum: salah satu penentu jalannya sebuah pendidikan tidak terlepas dari kurikulum. Ciri-ciri dan isi kurikulum dalam pendidikan, khsusunya pendidikan dasar Islam harus menonjolkan pendidikan akhlak dan moral. Kurikulum yang betul-betul mencerminkan semangat, pemikiran dan ajaran yang menyeluruh, bersikap

\footnotetext{
16Janan, Pendidikan, 98

${ }^{17}$ Abuddin Nata, Pemikiran...., 209
} 
seimbang antara berbagai ilmu yang dikandung dalam kurikulum yang akan digunakan, menyeluruh dalam menata seluruh mata pelajaran yang diperlukan oleh peserta didik, dan disesuaikan dengan minat dan bakat anak peserta didik.

3. Membantu dalam merumuskan ciri-ciri guru profesional: salah satu penentu seorang guru profesional dapat dilihat dari akhlaknya. Jika akhlak seorang guru baik bisa dipastikan dalam menjalankan tugasnyapun dia akan profesional. Sebagai calon guru profesional dalam pendidikan dasar Islam akhlak dan moralitas sangat menentukan dalam membentuk ciri-ciri guru profesional. Guru pendidikan dasar Islam selain memiliki kompetensi akademik, pedagogik dan sosial, juga harus memiliki kompetensi keperibadian. Yaitu peribadi yang beriman, bertakwa, ikhlas, sabar, zuhud, pemaaf, penyayang, mencintai dan melindungi, satu kata dan perbuatan, adil demokratis, manusiawi, rendah hati, senantiasa menambah ilmu dan pengalaman dan murah senyum. Akhlak-akhlak seperti itulah yang seharusnya tercermin dalam pribadi seorang guru pendidikan dasar Islam.

4. Membantu merumuskan kode etik dan tata tertib Pendidikan dasar Islam: pemahaman terhadap akhlak dan moralitas dapat membantu dalam merumuskan kode etik dan tata tertib sekolah, khususnya yang berkenaan dengan akhlak para peserta didik. Kode etik dan tata tertib yang diterapkan melalui akhlak akan menjadikan seorang guru terasa dihormati sehingga suasana pembelajaran akan berjalan kondusif, semangat dalam menyampaikan materi juga akan berjalan dengan baik. Selanjutnya dalam proses pembelajaran suasana kelas akan tertib dan tenang, hubungan sesama akan terasa akrab, suasana akademik akan terasa kental, lingkungan belajar akan nyaman, aman dan damai, serta perestasi belajar para siswa akan meningkat.

5. Melahirkan manusia yang memiliki akhlak mulia dan karakter utama: sesuai tujuan akhir yang ingin dicapai dalam pendidikan dasar Islam begitujuga dalam pendidikan akhlak menjadikan peserta didik sosok yang memiliki akhlak mulia dan mempunyai karakter utama. Dengan adanya akhlak dan moralitas dalam pendidikan dasar Islam tentunya akan melahirkan peserta didik yang berkrpibadian akhlak mulia dalam kehidupan sehari-hari. Sehingga nanti ketika dewasa anak akan memiliki jiwa yang selalu menebar kasih sayang dan menagamalkan akhlak mulia.

6. Membantu menciptakan lingkungan pendidikan yang kondusif: pemahaman terhadap akhlak dan moralitas akan membantu mewujudkan lingkungan 
pendidikan dasar Islam yang bersih, tertib, aman, damai, nyaman, yang mendukung terciptanya suasana belajar yang kondusif. Ketika konseptual tentnag akhlak dan moralitas diterapkan tentu akan menghasilkan pembelajaran yang bersih dan peserta didik belajar dengan nyaman dan terhindar dari penyakit. Dalam konsep akhalk dan moralitas pengajaran tentang cinta kebersihan, bersih jasmani dan rohani merupakan ajaran yang termuat dalam pendidikan akhlak dan moralitas. Lingkungan yang kondusif dalam pendidikan dasar Islam akan menjadikan peserta didik terhindar dari berbagai penyakit, dan terbiasa menyukai kebersihan dalam hidupnya.

\section{Kesimpulan}

Pengertian Akhlak sangat luas tidak hanya sekedar baik, buruk, etika dan moral. Akhlak menyangkut hubungan vertikal dan horizontal. Akhlak bersumber dari wahyu sedangkan yang lainnya berasal dari pemikiran manusia. Akhlak terbagi: akhlak kepada Allah, Rasul, diri sendiri, keluarga, lingkungan, alam dan negara.Yang menjadi dasar-dasar akhlak adalah berupa al-Qur'an dan Sunnah Nabi Muhammad Saw. Serta akal dan nurani manusia serta pandangan umum masyarakat. Implikasi pandangan Islam tentang akhlak mewajibkan pendidikan Islam agar membangun akhlak Islamiah pada peserta didik, baik yang menyangkut hubungan dengan Allah maupun dengan manusia dan sesama makhluk. Di awali dengan pengajaran dilanjutkan dengan cara pendidikan melalui pembiasaan, keteladanan, pengamalan, dibarengi contoh, serta penjelasan. Terus dibina demikian hingga akhimya menjadi kebiasaan dan karakter.Kontribusi akhlak terhadap pendidikan dasar Islam ialah:pemahaman tentang akhlak membantu merumuskan tujuan pendidikan, membantu dalam merumuskan ciri-ciri dan kandungan kurikulum, membantu dalam merumuskan ciri-ciri guru profesional, membantu merumuskan kode etik dan tata tertib sekolah, membantu kegiatan belajar mengajar, membantu menciptakan lingkungan pendidikan yang kondusif.

\section{Daftar Pustaka}

Arifin, Muzayyin, 2003. Filsapat Pendidikan Islam, Jakarta: Bumi Aksara.

Asifuddin, Ahmad Janan, 2010. Mengikuti Pilar-Pilar Pendidikan Islam, Yogyakarta: SUKA-Press.

Assegaf, Rachman, 2011. Filsapat Pendidikan Islam, Jakarta: Raja Grafindo Persada. 
112 | AR-RIAYAH : Jurnal Pendidikan Dasar vol. 2, no. 2, 2018

Juwariyah, 2008. Pendidikan Moral Dalam Puisi Imam Syafi i dan Ahmad Syanqi, Yogyakarta: Bidang Akademik.

Lahiji,Qurbani, 2011.Risalah Sang Imam (AjaranEtika Ali Bin AbiThalib), Jakarta: al-Huda.

Marjuki, 2009. AkblakMulia (PengantarStudiKonsep-KonsepDasarEtikaDalam Islam), Yogyakarta: Debut Wahana.

Nata, Abuddin, 2012. Pemikiran Pendidikan Islam dan Barat, Jakarta: Rajawali Press.

Nata, Abudin, 2017. Akblak Tasawnf dan Karakter Mulia, Jakarta: Rajawali Press.

Tafsir, Ahmad, 2004. Ilmu Pendidikan Dalam Persfektif Islam, Bandung: Remaja Rosdakarya.

Tafsir Ahmad, 2015. Imu Pendidikan Islam, Bandung: Remaja Rosdakarya.

Widodo, Semboro Ardi, 2003. Kajian Filosofis Pendidikan Barat dan Islam, Jakarta: Fifamas. 